\title{
S ORGERY
}

UNDER THE CEARGE OF

T. TURNER THOMAS, M.D.,

ABSOCIATE PROFESBOR OF APPLIED ANATOMT AND AGSOCLATE IN SURGERY IN THE TNTVERSTT OF PENTGYLYANLA; BURGEON TO THE PHILADELPBLA GENERAL HOSPITAL AND ABSISTANT BUEGEON TO THE ONIVERSITY IIOSPITAL.

Transplantation of Fascia for Pointed-toe Deformity.-OrTh ( $Z_{c n-}$ tralbl. $f$. Chir., 1916, xliii, 812) says that pointed-toe deformity has increased of late in military and non-military service. In many cases gymnastic and other corrective exercises were unsuccessful, and only operation gave hope of making the patients useful. So long as the tendons are not too much contracted or degenerated by cicatricial tissue, the methods of Beyer and Vulpius are sufficient. But when these conditions do exist or the original lesion affects the tendon itself, we may lengthen the tendon by the transplantation of a suitable piece of fascia to fill the gap resulting from the division of the tendon. The transplanted piece of fascia did not become recrotic or contract. Passive movements were begun after fourteen days and active movements after three to four weeks. The results were good in three soldiers so operated on. Two of them returned to service in the field and one to garrison duty.

Proving the Collateral Circulation in a Case of Femoral Aneurysm by the Henle-Coenen Sign.-Dreyer (Zentralbl. f. Chir., 1916, xliii, 825) proceeded as follows in a case of aneurysm in Hunter's canal: He exposed the femoral vessels central to the aneurysm in an easily accessible place and clamped the artery here. He then isolated the vessels in the popliteal space, and divided a lateral branch of the popliteal artery. The free bleeding from the central end of the divided branch proved a sufficient collateral circulation to justify the application of a simple ligature to the femoral artery on the central side and another to the popliteal artery on the peripheral side of the aneurysm. There was not the slightest disturbance in nutrition. The patient got out of bed on the eighth day and walked around. The author offers the ' following modification of the proof of the condition of the collateral circulation: The application of a preliminary clamp on the peripheral as well as on the central side of the aneurysm.

The Electromagnet in War Surgery.-Conds (Zentralbl. f. Chir., 1916, xliii, 865) refers to Capelle's article on the treatment of erysipelas with artificial sunlight and relates his own experience with the method. $\mathrm{He}$ begins with daily ten-minute exposures and obtains favorable results. Recently he began to use exposures to the rays of the sun. According to his small experience, the exposure to the free air and sun is to be preferred to the exposure to artificial sunlight. One patient with recurring erysipelas and a perforating, sequestrating, gunshot 